http://jmscr.igmpublication.org/home/ ISSN (e)-2347-176x ISSN (p) 2455-0450

crossref DOI: https://dx.doi.org/10.18535/jmscr/v7i9.31

\title{
A clinical study of management of unstable Intertrochantric Fractures with Proximal Femoral Nail
}

\author{
Authors \\ Dr Jaising Rathod", Dr B Vishwanath Naik ${ }^{2 *}$, Dr Sandeep Vemula ${ }^{3}$ \\ ${ }^{1,2}$ Associate professor, Department of Orthopedics, Kakatiya Medical College and MGM hospital, \\ Warangal, 506007 \\ ${ }^{3}$ Senior Resident, Department of Orthopedics, Kakatiya Medical College and MGM hospital, Warangal, \\ 506007 \\ *Corresponding Author \\ B Vishwanath Naik
}

Associate Professor, Department of Orthopedics, MGM Hospital Warangal-50600, India

\begin{abstract}
The objective of the present study was to evaluate the efficacy of proximal femoral nail in the management of unstable intertrochanteric fractures of the hip in different age group and to determine the clinical, radiological and functional outcomes at the end of 6 months of follow up.

Methods: This is a prospective study was done in the Department of Orthopedics Kakatiya Medical College and Mahatma Gandhi Hospital, Warangal. The patients with intertrochanteric fractures underwent surgical treatment with the proximal femoral nail with a follow-up period of 12 months. A standard surgical approach was used during the operative procedure Quadriceps physiotherapy: Strengthening exercises, Static quadriceps exercise, and calf pumping are started soon, followed by knee and ankle mobilization on post-op day 1. Sutures were removed on 12th post-Operative day. Patients were advised to walk non-weight bearing as soon as tolerable depending upon the fracture pattern.

Results: The total number of cases in this study was $n=25$ of which $n=16(64 \%)$ were males and $n=9(36 \%)$ were females. Boyd and Griffin Classification of intertrochanteric fractures in the study shows type II were found the most common involving $n=14(56 \%)$ of the patients followed by type III $n=5(20 \%)$. The type I were found in $n=4(16 \%)$ and type IV was found in $n=2(8 \%)$ The Harris hip score at the end of 6 months revealed excellent scores in $68 \%$ of the patients good score in $24 \%$, fair score in $4 \%$ and poor score in $4 \%$ of the patients.
\end{abstract}

Conclusion: proximal femoral nail is a good choice in cases of unstable intertrochanteric fractures of femur because it serves a buttress against the lateral translation of the proximal fragments. It also replaces the comminuted lateral wall which is useful in unstable fractures. The implant temporarily compensates for the function of the medial column.

Keywords: Unstable Intertrochanteric Fractures, Proximal Femoral Nail.

\section{Introduction}

Intertrochanteric fractures are one of the common types of hip fractures. The anatomic locations of these types of fractures are in the upper proximal part of the femur. The proximal femur consists of the femoral head, neck, and the trochanteric region. An intertrochanteric hip fracture occurs between the greater trochanter, at the attachment 
of gluteus medius and gluteus minimus and lesser trochanter at the attachment of iliopsoas muscle. Intertrochanteric femoral fractures are common in the elderly patient and are the most frequently operated fractures and have the highest morbidity and mortality rates ${ }^{[1,2]}$. The frequency of these fractures is on risk due to rise in aging population and sedentary lifestyles mostly due to trivial trauma. In the young population, the cause of trochanteric fractures is often related to highvelocity trauma. Gulberg et al; have predicted that the total number of hip fractures may rise to 2.6 million by 2025 and 4.5 million by $2050^{[3]}$. Due to osteoporosis and poor bone quality, achieving stable fixation in elderly patients is quite difficult 4 Stable fixations and early mobilization is the principle of treatment of such fractures [5, 6]. Conservative management of trochanteric fractures also results in acceptable results and union of fractures. However, if suitable precautions are not taken then fractures undergo malunion, leading to varus and external rotation deformity at the fracture site and shortening of limb and limitation of movements of the hip.

Immobilization of older patients is associated with problems like DVT, hypostatic pneumonia, catheter sepsis, cardiorespiratory failure, decubitus ulcer, and joint contractures. Therefore, early mobilization is required to reduce and prevent co-morbidities associated with such fracture treatment. Studies have shown that prolonged immobilization is associated with increased mortality rates following conservative treatment ${ }^{[7]}$. The most preferred method for treatment for intertrochanteric fractures is surgery except in cases of terminal illnesses, unresolved life-threatening medical comorbidities ${ }^{[2]}$. Various implants are available for the treatment of intertrochanteric femur fractures with their advantages and disadvantages. Sliding hip screw or dynamic hip screw is associated with more blood loss, soft tissue dissections which may deteriorate the preexisting morbidities excessive medialization of the distal fragment (unstable fracture), cutting out of the screw and collapse upon weight-bearing are also major drawbacks ${ }^{[8-}$
10]. Gamma nail is associated with cutting out of the screw, thigh pain and femoral shaft fractures [11-14]. Proximal femoral nail is generally more stable under loading with a shorter lever arm, so the distance between the hip joint and the nail is reduced compared with plates thus reduces chances of varus collapse ${ }^{[15]}$. The advantages are smaller incision, less blood loss, lesser soft tissue trauma and significantly decreases morbidities associated with such fracture ${ }^{[15]}$. Hence we in the present study tried to evaluate the outcomes of the unstable Intertrochanteric Fractures with treated with Proximal Femoral Nail.

\section{Material and Methods}

This is a prospective study was done in the Department of Orthopedics Kakatiya Medical College and Mahatma Gandhi Hospital, Warangal. The patients with intertrochanteric fractures underwent surgical treatment with the proximal femoral nail with a follow-up period of 12 months. Written consent was obtained from all the participants of the study. A total of $n=25$ patients were selected for the study based on the inclusion and exclusion criteria. Inclusion criteria were adults of both sexes and all closed unstable intertrochanteric fractures treated with the proximal femoral nail. Exclusion criteria were patients of polytrauma, associated with lower extremity fractures other than a femur, malignancy, and altered biochemical parameters which interfere with fracture healing.

After the patient with intertrochanteric fracture was admitted to our hospital, all the necessary clinical details were recorded in the proforma prepared for this study. After the completion of the hospital treatment patients were discharged and called for a follow-up to the outpatient department at regular intervals (6weeks, 12 weeks, 6months, and 12 months) for clinical and radiological evaluation. The patients were followed up till fracture union \& yearly once from then-on. Preoperative evaluation Radiological: Preoperative X-ray pelvis with both hips anteroposterior and lateral views were taken. Preoperative radiological evaluation was taken to 
confirm the diagnosis. Surgical work up Routine preoperative laboratory evaluation including complete blood cell count, electrolytes, coagulation profile, urinalysis, ECG and Chest Roentgenogram were done. Patients receiving anticoagulant medications were stopped for five days before surgery. After pre-anesthetic checkup patient was taken up for surgery. Pre-op planning: Determination of nail diameter: Nail diameter was determined by measuring the diameter of the femur at the level of the isthmus on an AP X-ray. Length of Nail: The length of the standard nail is $25 \mathrm{~cm}$ and long length nail is measured from the tip of the greater trochanter to upper pole of the patella. In the present study, we used nails of the standard length of $25 \mathrm{~cm}$ \& long length nails ranging from $36-42 \mathrm{~cm}$. The diameter of the standard nail was ranging from $9-12 \mathrm{~mm}$ and length nails were ranging from $9-11 \mathrm{~mm}$. The nail is universal with 6 degrees of mediolateral valgus angulation and with the neck-shaft angle of 135 degrees. Spinal / Epidural anesthesia was given in most of the cases but some cases required general anesthesia. A standard surgical approach was used during the operative procedure the mean duration of surgery was $50.3 \pm 11.9$ minutes. Postoperative antibiotics: inj. Ceftriaxone 1gm IV 12 hourly was continued for the first 3 days and then it was shifted to oral. Suction drainage was removed after 24 hours in case of open reduction. I.V. analgesics were given for 1 day followed by oral analgesics when necessary. Quadriceps physiotherapy: Strengthening exercises, Static quadriceps exercise, and calf pumping are started soon, followed by knee and ankle mobilization on post-op day 1 . Sutures were removed on 12 th postOperative day. Patients were advised to walk nonweight bearing as soon as tolerable depending upon the fracture pattern. Partial weight-bearing walking was started once further collapse is not expected radiologically in case of stable fractures where comminution is minimal. Full weightbearing walking was allowed after assessing for the radiological and clinical union. Hospital stay: Patient is discharged as soon as the wound and general condition of the patient is satisfactory, around 3rd post-operative day. Follow up The patients were asked to follow up at 6 weeks, 3months, 6 months, 12 months from the date of surgery. At each follow-up, the patient was assessed clinically as per Harris Hip score and $\mathrm{x}$ ray AP/Lateral views of the hip with femur is taken. They were evaluated with HARRIS HIP $\mathrm{SCORE}^{77} \& \mathrm{X}$-rays.

\section{Results}

The total number of cases in this study was $n=25$ of which $n=16(64 \%)$ were males and $n=9(36 \%)$ were females. Most of the cases in this study were belonging to the age group $60-70$ years with $\mathrm{n}=8(32 \%)$ of the cases followed by $\mathrm{n}=7(28 \%)$ in $>$ 70 years of age group. This shows that Intertrochanteric Fractures are common in an old age group other details are shown in table 1.

Table 1: Showing age and sex-wise distribution of cases in the study

\begin{tabular}{|l|c|c|c|c|}
\hline \multirow{2}{*}{ Age in years } & \multicolumn{2}{|c|}{ Noof patients } & Total & $\begin{array}{c}\text { \% of } \\
\text { patients }\end{array}$ \\
\cline { 2 - 5 } & Male & Female & & 8 \\
\hline $\mathbf{3 0 - 4 0}$ & 1 & 1 & 2 & 16 \\
\hline $\mathbf{4 0 - 5 0}$ & 3 & 1 & 4 & 16 \\
\hline $\mathbf{5 0 - 6 0}$ & 3 & 1 & 4 & 32 \\
\hline $\mathbf{6 0 - 7 0}$ & 5 & 3 & 8 & 28 \\
\hline$>\mathbf{7 0}$ & 4 & 3 & 7 & 100 \\
\hline Total & 16 & 9 & 25 & \\
\hline
\end{tabular}

The mode of injury was trivial trauma after a fall in $n=17(68 \%)$ of cases and RTA in $n=8(32 \%)$ of cases. The right side was involved in $n=14(56 \%)$ of cases and the left side was involved in $\mathrm{n}=11(44 \%)$ of cases. In the study, the fractures were classified as per Boyd and Griffin classification of intertrochanteric fractures type II was found the most common involving $\mathrm{n}=14$ $(56 \%)$ of the patients followed by type III $\mathrm{n}=5(20 \%)$. The type I were found in $\mathrm{n}=4(16 \%)$ and type IV was found in $n=2(8 \%)$ shown in table 2.

Table 2: Intertrochanteric fractures are classified according to Boyd and Griffin Classification

\begin{tabular}{|l|c|c|c|c|}
\hline \multirow{2}{*}{ Type of Fracture } & \multicolumn{2}{|c|}{ No. of Patients } & \multirow{2}{*}{ Total } & \multirow{2}{*}{$\%$} \\
\cline { 2 - 3 } & Male & Female & Total & $16 \%$ \\
\hline Type I & 3 & 1 & 4 & $56 \%$ \\
\hline Type II & 9 & 5 & 14 & $20 \%$ \\
\hline Type III & 3 & 2 & 05 & $08 \%$ \\
\hline Type IV & 1 & 1 & 02 & 080 \\
\hline Total & 16 & 9 & 25 & 100 \\
\hline
\end{tabular}


The presence of co-morbidities in the patients were recorded during the study, out of $n=25$ patients $\mathrm{n}=15(60 \%)$ were having hypertension, COPD in $\mathrm{n}=8$ (32\%), Diabetes mellitus was in $\mathrm{n}=11(44 \%)$, Bronchial asthma and anemia in $\mathrm{n}=6(24 \%)$ each, IHD in $\mathrm{n}=3(12 \%)$ of patients Electrolyte imbalance in $n=2(8 \%)$ of the patients. The most common type of intramedullary hip screws used during the treatment was long IMHS in $\mathrm{n}=14(56 \%)$ and standard screws were used in $\mathrm{n}=11(44 \%)$ of the patients (table 4$)$.

Table 4: Type of Intramedullary Hip Screws used during treatment

\begin{tabular}{|l|c|c|c|c|}
\hline Type of IMHS & Male & Female & $\begin{array}{c}\text { No. of } \\
\text { Patients }\end{array}$ & $\begin{array}{c}\text { \% of } \\
\text { cases }\end{array}$ \\
\hline Standard IMHS & 7 & 4 & 11 & $44 \%$ \\
\hline Long IMHS & 9 & 5 & 14 & $56 \%$ \\
\hline Total & 16 & 9 & 25 & 100 \\
\hline
\end{tabular}

The intraoperative complications were recorded during the surgery, most common complication faced was a failure to achieve closed reduction was observed in subtrochanteric fractures 2 cases and 1 case of reverse oblique fracture total $\mathrm{n}=3(12 \%)$ and fracture displacement by nail insertion was seen in $n=1(4 \%)$ shown in table 5 . The postoperative complications included knee stiffness in $n=2(8 \%)$, malunion in $n=1(4 \%)$, there were total $n=3(12 \%)$ cases found with postoperative complications they were managed adequately and all of them recovered to a satisfactory outcome.

Table 5: Intraoperative complications of IMHS in the study

\begin{tabular}{|l|c|c|c|c|}
\hline Type of IMHS & Male & Female & $\begin{array}{c}\text { No. of } \\
\text { Patients }\end{array}$ & $\begin{array}{c}\% \text { of } \\
\text { cases }\end{array}$ \\
\hline $\begin{array}{l}\text { Failure to achieve a closed } \\
\text { reduction }\end{array}$ & 2 & 1 & 3 & $12 \%$ \\
\hline $\begin{array}{l}\text { Fracture displacement by nail } \\
\text { insertion }\end{array}$ & 0 & 1 & 1 & $4 \%$ \\
\hline Fracture of the lateral cortex & 0 & 0 & 0 & $0 \%$ \\
\hline Total & 2 & 2 & 4 & 100 \\
\hline
\end{tabular}

A follow up of the patients at the end of 6 months radiologically revealed most of the case $\mathrm{n}=23(92 \%)$ were showing the union of fractures and varus malalignment and nonunion was seen in $\mathrm{n}=1(4 \%)$ cases each shown in table 6 .
Table 6: Radiographic assessment of treatment at follow up after 6 months

\begin{tabular}{|l|c|c|c|c|}
\hline Type of IMHS & Male & Female & $\begin{array}{c}\text { No. of } \\
\text { Patients }\end{array}$ & $\begin{array}{c}\% \text { of } \\
\text { cases }\end{array}$ \\
\hline United in varus & 1 & 0 & 1 & $4 \%$ \\
\hline $\begin{array}{l}\text { United } \\
\text { malalignment }\end{array}$ & 0 & 1 & 1 & $4 \%$ \\
\hline Nonunion & & 8 & 23 & $92 \%$ \\
\hline
\end{tabular}

Most of the patients were able to bear to do partial weight bearing by 1-3 weeks and by the end of 3 months total 21 patients could do partial weightbearing and 1 patient did not follow the postoperative protocol and did full weight-bearing immediately after surgery. The Harris Hip Score $^{[16]}$ at the end of 6 months revealed excellent scores in $68 \%$ of the patients, good score in $24 \%$, fair score in $4 \%$ and poor score in $4 \%$ of the patients.

Table 7: Harris $\mathrm{Hip}^{[16]}$ scoring at the end of 6 months

\begin{tabular}{|l|c|c|c|c|}
\hline Score & Male & Female & $\begin{array}{l}\text { No. Of Patients } \\
\text { (Total 22cases) }\end{array}$ & $\begin{array}{c}\text { \% Of } \\
\text { Patients }\end{array}$ \\
\hline $\begin{array}{l}\text { 90-100 } \\
\text { Excellent }\end{array}$ & 11 & 6 & 17 & $68 \%$ \\
\hline 80-89 - Good & 3 & 3 & 06 & $24 \%$ \\
\hline $\mathbf{7 0 - 7 9}$ - Fair & 1 & 0 & 01 & $4 \%$ \\
\hline$<70$ - Poor & 0 & 1 & 01 & $4 \%$ \\
\hline
\end{tabular}

\section{Discussion}

Intertrochanteric femur fractures present a challenge to the orthopedic surgeon for achieving fracture union and restoration of optimal functions. This study aimed to find the outcomes of unstable intertrochanteric femur fractures treated with a femoral proximal femoral nail. The most common age group involved in the femur fractures according to this study was 60 to 70 years age group followed by people of $>70$ years age this signifies that the old age group are more prone to this kind of fracture which is by low energy trauma like fall at home other similar studies have shown similar findings in older age group of patients ${ }^{[17-20]}$. Gallagher et al; in their study have found an eight-fold increase in intertrochanteric fractures in men over 80 years and women over 50 years age group ${ }^{[21]}$. The main cause of fractures in this age group is because senile osteoporosis mainly affects trochanteric regions commonly and hip joint being one of the 
major joints in weight-bearing the already weakened part cannot withstand sudden abnormal stress. The trabecular spaces are enlarged in this area and loaded with fat while covering compact tissue is thinned out and calcar is usually atrophied. Cleveland et al; ${ }^{[22]}$ have shown a higher incidence of multiple fractures of the same side or opposite side may occur along with intertrochanteric fractures. The younger people involved in this kind of fracture is due to road traffic accidents the incidence of RTA in our study was $\mathrm{n}=8(32 \%)$. Joseph Zuckerman (1996) observed that $90 \%$ of hip fractures in the elderly result from a simple fall. Hip fractures in young adults were observed to result most often with high energy trauma such as motor vehicular accidents or a fall from height. Dean GL et al; ${ }^{[23]}$ have stated that the mechanism of injury in this kind of fracture is not direct but due to failure of stresses resisting forces during sudden bending or twisting. A direct blow on the lateral aspect of the thigh can result in contusion, comminution on the lateral surface of the greater trochanter and causes valgus deformity. In the present study, we observed that $n=23(92 \%)$ of intertrochanteric fractures with a variable degree of comminution, $\mathrm{n}=2(8 \%)$ were subtrochanteric fractures which were treated with IMHS. Out of the total $n=25$ intertrochanteric fractures, 21 were found to be unstable fractures and 4 were stable fractures Boyd and Griffin type I. M Evans ${ }^{[24]}$ has described that intertrochanteric fractures are considered as stable or unstable depending on the integrity of posteromedial cortex. In the present study majority of cases were operated by IMHS were having a fracture of the left side. Most of the patients in the present study were operated within 48 hours of admission to the hospital in some cases operation was delayed to achieve surgical fitness in the presence of comorbidities. Reasonable time to surgery and early mobilization and rehabilitation is generally required to avoid complications in the older age group patients ${ }^{[25]}$. The Mean duration of surgery in the present study was 50.3 minutes with a standard deviation for 11.9 minutes $92 \%$ of the cases were done closed reduction was the fracture hematoma was preserved. In $8 \%$ of failure to achieve closed reduction so open reduction was done and a minimal amount of blood loss was there. The average blood loss in our study was $50 \mathrm{ml}$. Pajarinen et al; ${ }^{[26]}$ the average operating time was 55 minutes and the average blood loss was $320 \mathrm{ml}$. Liu XW et al; ${ }^{[27]}$ the average operating time as $46.5 \mathrm{~min}$ with a standard deviation of 20.5 minutes and an average blood loss of $136 \mathrm{ml}$. In the present study, there were no superficial or deep infections in post-operative period all the patients were given $3^{\text {rd }}$ generation cephalosporin up to three postoperative days followed by oral antibiotics till the suture removal. Simmermacher et al; ${ }^{[28]}$ in their study have reported an infection rate of $2 \%$ while Schipper et al; ${ }^{[29]}$ have reported superficial wound infections in $4.1 \%$ and deep infection in $2.5 \%$ of cases. Average time of union in all our patients was about 13 weeks (Range: 12 to 14 weeks) There is some controversy regarding criteria for the time of fracture union in different studies ${ }^{[30]}$. Some use radiological while some use radiological and clinical union. Radiologically, we have used criteria for the union as the presence of bridging callus at the fracture site. The Harris Hip score was excellent in 17 patients $(68 \%)$, good in 06 patients $(24 \%)$, Fair in 1 patient (4\%), Poor in 1 patient (4\%). The poor Harris hip score in this study was due to poor compliance of patients by unprotected early weight-bearing leading to fracture collapse due to osteoporosis. GN Kumar et al; ${ }^{[31]}$ in a similar study have found an excellent score in $35.7 \%$, Good in $42.8 \%$, Fair in $14.2 \%$, Poor in $7.1 \%$ of patients.

\section{Conclusion}

Within the limitations of the present study, it can be concluded that proximal femoral nail is a good choice in cases of unstable intertrochanteric fractures of femur because it serves a buttress against the lateral translation of the proximal fragments. It also replaces the comminuted lateral wall which is useful in unstable fractures. The implant temporarily compensates for the function of the medial column. The use of femoral nail for 
extra-capsular fractures of the proximal femur has several distinct advantages, namely; lesser operative time with less operative blood loss, early return to daily activities, reduced complications like infection, sliding, and limb length discrepancy.

\section{Conflict of interest: None \\ Source of support: Nil \\ Ethical Permission: Obtained}

\section{References}

1. Evans PJ, Mcgrocy BJ. Fractures of the proximal femur. Hospital Physician. 2002:38:30-38.

2. Bonnaire F, Zenker H, Lill C, Weber AT, Linke B. Treatment strategies for proximal femur fractures in osteoporotic patients. Osteoporos Int. 2005:16 Supp 2: S93S102.

3. Gullberg B, Johnell O, Kanis JA. Worldwide projection for hip fracture, osteoporosis international 1997; 7(5):40713.

4. Konal KJ, Cantu R V, Intertrochanteric fractures in Bucloz RN, Heckman Court brown LM, Torenetta IIIP, Mcqueen MM (7th edn) Rockwood \& Green fractures in adults (Wolters Kluwer; Lippincott Williams \& Wilkins 2010)

5. M. Saudan, A. Lubbeke, C. Sadowskil, N. Riand, R. Stern, P. Hoffmeyer. Pertrochanteric Fractures: Is There an Advantage to an Intramedullary Nail? A Randomized Prospectivee Study of 206 Patients Comparing the Dynamic Hip Screw and Proximal Femoral Nail. Journal of Orthopaedic Trauma 2002; 16(6): 38693.

6. J. Pajarinen, J. Lindahl, O. Michelsson, V. Savolainen, E. Hirvensalo, Pertrochanteric Femoral Fractures Treated with a Dynamic Hip Screw or a Proximal Femoral Nail. A Randomized Study Comparing PostOperative Rehabilitation, Journal of Bone and Joint Surgery 2005 Jan; 87 (1):76-81.
7. Babhulkar Sudhir S. Management of trochanteric Fractures. Indian Journal of Orthopaedics October 2006; 40(4): 21018.

8. Morris AH, Zuckerman JD, American Academy of Orthopaedic Surgeons Council of Health Policy and Practice. National Consensus Conference on Improving the Continuum of Care for Patients with Hip Fracture. J Bone Joint Surgery Am 2002; 84: 670-74.

9. Flores LA, Harrington IJ, Heller M. The stability of intertrochanteric fractures treated with a sliding screw-plate. J Bone Joint Surg Br 1990; 72:37-40.

10. Simpson AH, Varty K, Dodd CA. Sliding hip screws: modes of failure. Injury 1989; 20:227- 31 .

11. C.I. Adams, C.M. Robinson, C.M. CourtBrown, MM Mcqueen. Prospective Randomized Controlled Trial of an Intramedullary Nail versus Dynamic Screw and Plate for Intertrochanteric Fractures of the Femur, Journal of Orthopaedic Trauma 2001; 15(6): 394-00.

12. Bridle SH, Patel AD, Bircher M, Calvert PT. Fixation of intertrochanteric fractures of the femur. A randomized prospective comparison of the gamma nail and the dynamic hip screw. J Bone Joint Surg [Br] 1991; 73:330-34.

13. Hesse B, Gachter A. Complications following the treatment of intertrochanteric fractures with the gamma nail. Arch Orthop Trauma Surg 2004; 124:692-98.

14. Halder SC. The Gamma nail for peritrochanteric femur fractures. J Bone Joint Surg Br 1992; 74:340-44.

15. Domingo LJ, Cecilia D, Herrera A, Resines C. Trochanteric fractures treated with a proximal femoral nail. Int Orthop 2001; 25(5): 298-01.

16. Harris WH. Traumatic arthritis of the hip after dislocation and acetabular fractures: treatment by mold arthroplasty. An 
end- result study using a new method of result evaluation. J Bone Joint Surg Am 1969; 51: 737- 55.

17. J. Pajarinen, J. Lindahl, O. Michelsson, V. Savolainen and E. Hirvensalo, Pertrochanteric Femoral Fractures Treated with a Dynamic Hip Screw or a Proximal Femoral Nail. A Randomized Study Comparing Post-Operative Rehabilitation. Journal of Bone and Joint Surgery 2005; 87(1):76-81.

18. Leung KS5 So WS, Sien WY, Hui PW. Gamma nail and dynamic! hip screws for peritrochanteric fractures. J Bone Joint Surg (Br). 1992;

19. Babhulkar Sudhir S. Management of trochanteric Fractures Department of Orthopaedics, Indira Gandhi Medical College, Nagpur. Indian Journal of Orthopaedics October 2006; 40 (4):210-18.

20. Miedel R, Ponzer S, Tornkvist $H$, Soderqvist A, Tidermark J. The standard Gamma nail or the Medoff sliding plate for unstable trochanteric and subtrochanteric fractures: A randomized, controlled trial. J Bone Joint Surg Brit 2005; 87: 68-75.

21. Gallangher JC, Melton LJ, Riggs BL et al. Epidemiology of fractures of the proximal femur in Rocester, Minnesota. Clinical Orthop 1980; 150:163-71.

22. Mather Cleveland: A ten-year analysis of intertrochanteric fractures, JBJS 1983;63B, 218.

23. Dean GL, David S-Jason HN. Osteoporotic pertrochateric fractures; Management and concurrent controversies. J Bone Jt Surg 2004; (Am) 72-B:737-52.

24. Evans EM. The treatment of trochanteric fractures of the femur. J Bone Joint Surg Br.1949;31B (2):190-203.
25. Heinz T, Vescei V. Complications and errors in use of the gamma nail. Causes and prevention. Chirurgie 1994; 65: 94352.

26. Pajarinen J, Lindahl J, Michelsson O, Savolainen V, Hirvensalo E. Pertrochanteric femoral fractures treated with a dynamic hip screw or a proximal femoral nail - A randomized stdy comparing post-operative rehabilitation. The Journal of Joint \& Bone Surgery $(\mathrm{Br})$ Jan 2005; 87(1): 76-81.

27. Liu XW, Zhang CC, Su JC, Fu QG, Yu $\mathrm{BQ}, \mathrm{Xu}$ SG. Treatment of trochanteric fractures of elderly with dynamic hip screw and proximal femoral nail (singlecenter, randomized and prospective research). Chinese Journal of Bone and Joint Injury. Chinese. 2009;24(9):796-97.

28. Simmermacher RKJ, Bosch AM, Van der Werken C. The AO/ASIF - proximal femoral nail: A new device for the treatment of unstable proximal femoral fractures. Injury 1999; 30: 327-32.

29. Schipper IB, Marti RK, van der Werken C. Unstable trochanteric femoral fractures: extramedullary or intramedullary fixation. Review of literature. Injury.2004; 35(2):142- 51.

30. Windoff J, Hollander D A, Hakmi M, Linhart W, Pitfalls \& complications in the use of proximal femoral nail Lagenbecks arch Surg 2005; 3901(1) Epub 2004 Apr 15.

31. G.N. Kiran Kumar, Gaurav Sharma, Kavin Khatri; Treatment of unstable Intertrochanteric Fractures with Proximal Femoral Nail Antirotation II: Our Experience in Indian Patients the Open Orthopaedics Journal 2015; 9: 456-59. 